
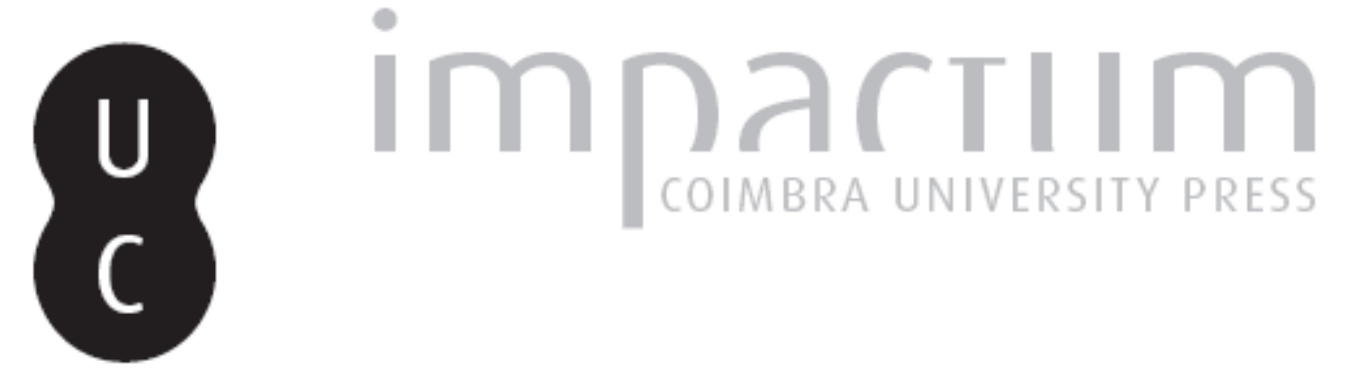

\title{
Metáforas de la guerra en el Erótico de Plutarco
}

Autor(es): Valverde Sánchez, Mariano

Publicado por: International Plutarch Society

URL persistente:

URI:http://hdl.handle.net/10316.2/37596

DOI:

DOI:http://dx.doi.org/10.14195/0258-655X_2_9

Accessed : $\quad$ 26-Apr-2023 08:53:16

A navegação consulta e descarregamento dos títulos inseridos nas Bibliotecas Digitais UC Digitalis, UC Pombalina e UC Impactum, pressupõem a aceitação plena e sem reservas dos Termos e Condições de Uso destas Bibliotecas Digitais, disponíveis em https://digitalis.uc.pt/pt-pt/termos.

Conforme exposto nos referidos Termos e Condições de Uso, o descarregamento de títulos de acesso restrito requer uma licença válida de autorização devendo o utilizador aceder ao(s) documento(s) a partir de um endereço de IP da instituição detentora da supramencionada licença.

Ao utilizador é apenas permitido o descarregamento para uso pessoal, pelo que o emprego do(s) título(s) descarregado(s) para outro fim, designadamente comercial, carece de autorização do respetivo autor ou editor da obra.

Na medida em que todas as obras da UC Digitalis se encontram protegidas pelo Código do Direito de Autor e Direitos Conexos e demais legislação aplicável, toda a cópia, parcial ou total, deste documento, nos casos em que é legalmente admitida, deverá conter ou fazer-se acompanhar por este aviso.

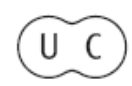




\section{Ploutarchos, n.s.}

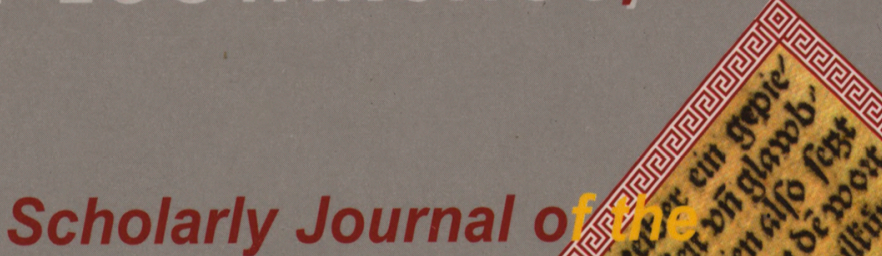

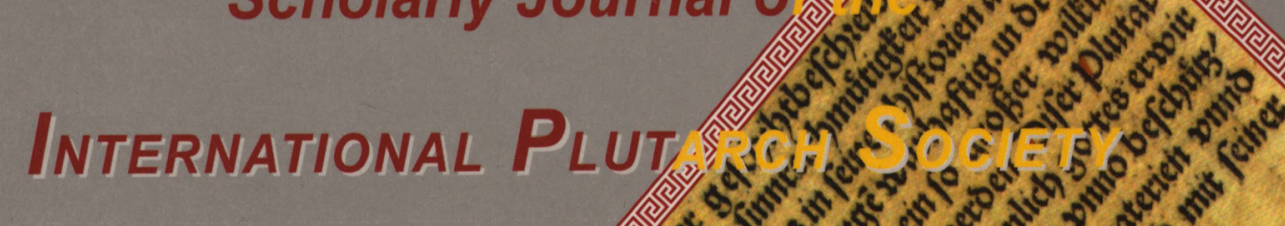

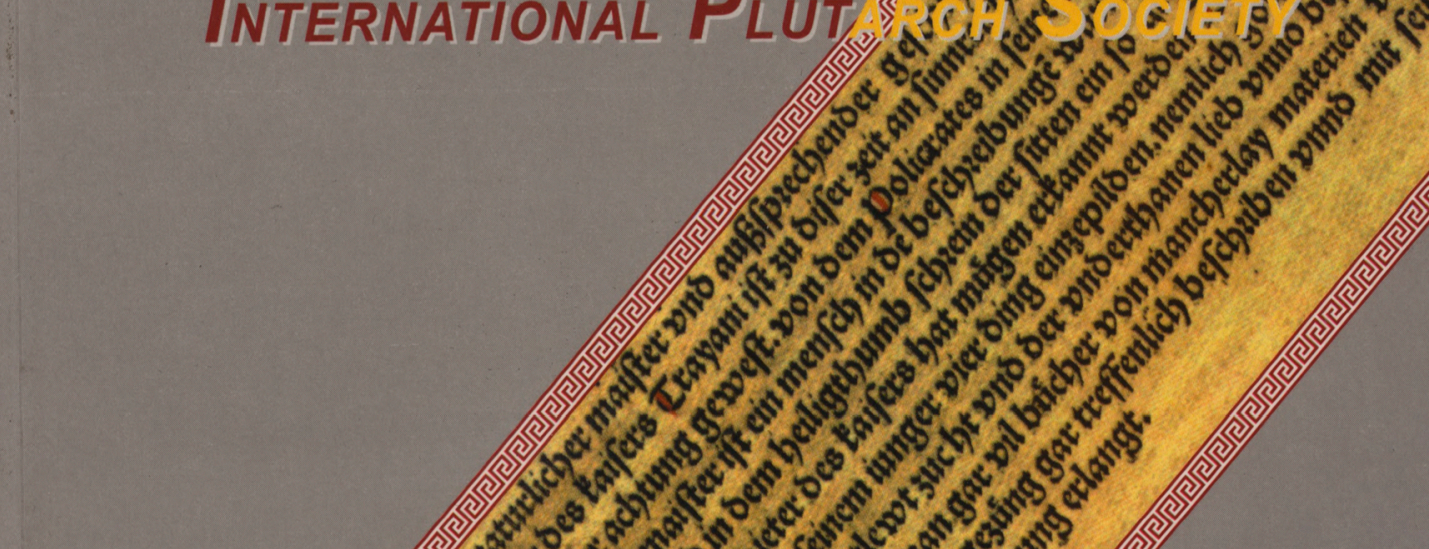




\title{
Metáforas de la guerra en el ERótico de Plutarco por \\ Mariano Valverde Sánchez \\ Universidad de Murcia
}

\begin{abstract}
This paper analyses the numerous metaphors of war present in Plutarch's Amatorius that are linked to the two key plots in the dialogue: the conversation on

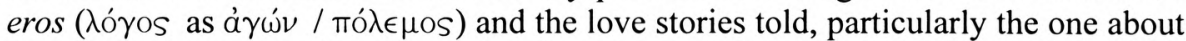
Bacchon and Ismenodora ( $€ \rho \omega s$ as $\mu a ́ x \eta / \pi o ́ \lambda \epsilon \mu O S$ ). We emphasize the relevance and integration of the metaphors in their context and underline the crucial functionality of these images for the overall meaning of the text.
\end{abstract}

El estilo de Plutarco se caracteriza en general por una gran riqueza de imágenes, metáforas, símiles, ejemplos, anécdotas y citas literarias. Tales recursos, que poseen una importante funcionalidad como ilustración del pensamiento, confieren a la prosa plutarquea una notable variedad temática y dotan al texto de una cuidada elaboración artística, que refleja la voluntad de estilo y el interés estético del escritor de Queronea ${ }^{1}$. En el caso del Amatorius, compuesto en la plenitud literaria del

autor y que, como ha escrito con razón Italo Gallo" , "può considerarsi il miglior prodotto plutarcheo nel genere dialogico", su rico lenguaje coloreado de abundantes metáforas lo sitúa entre las obras plutarqueas con mayor densidad de imágenes ${ }^{3}$. En particular el campo léxico de la guerra suministra un interesante material para la creación de expresiones figuradas relativas a la situación misma del diálogo, a la confrontación dialógica y al ámbito del

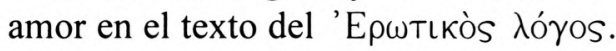

El tema de la guerra, presente en

1 En general puede verse la actualización de J. A. Fernández Delgado, 1992, pp. 31-63. Para el estudio de las imágenes contamos con el libro clásico de M. FunRmanN, 1964. La importancia de las imágenes para el pensamiento plutarqueo es evidenciada en la reciente monografía de R. HIRSCH-LUIPOLD, 2002.

2 "Strutture letterarie dei Moralia di Plutarco: aspetti e problemi", en J.A. FernÁndeZ DElgADO \& F. PORDOMINGO (eds.), Estudios sobre Plutarco: Aspectos formales, Madrid, 1996, pp. 3-16 (p. 14).

3 Pueden cotejarse los datos ofrecidos por M. FunRMAnN, 1964, pp. 20-23; y también M. VALVERDE, 1999, pp. 501-516. 
numerosas imágenes a lo largo de la obra plutarquea ${ }^{4}$, posee notable importancia en el pensamiento de nuestro autor ${ }^{5}$. En efecto, Plutarco vive el ambiente sociopolítico de la pax romana, donde la guerra parece un asunto ajeno a la realidad contemporánea ${ }^{6}$, pero la historia griega está dominada por los enfrentamientos bélicos que de algún modo forman parte de la memoria colectiva helénica. Para el queronense en general la guerra es considerada un mal, que está en la naturaleza humana y viene a ser resultado de sus vicios $^{7}$. De igual modo que alaba la ónóvola y cierta ịouxía temporal, así la ausencia de guerra (mó $\lambda \in \mu \circ S)$ y de lucha civil ( $\sigma \tau a ́ \sigma \iota s)$ constituye uno de los preciados bienes que permiten al hombre gozar de $\epsilon \dot{\theta} \theta v \mu i ́ a$, el anhelado "sosiego espiritual" (Mor. 469e).

Antes de adentrarnos en el análisis de las imágenes bélicas presentes en el Amatorius, parece conveniente estable- cer algunas precisiones metodológicas en torno al concepto de metáfora y a la orientación concreta de nuestro trabajo. Según la conocida definición aristotélica, "metáfora es la aplicación a un referente de una palabra distinta, transferencia que se produce bien del género a la especie, bien de la especie al género, bien de la especie a la especie, bien por analogía"8. Los tres primeros casos responden más bien a la transferencia por contigüidad subyacente en la metonimia y la sinécdoque. Al último supuesto correspondería la metáfora propiamente dicha, que en virtud de un proce-

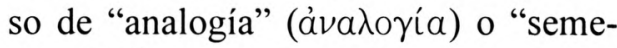

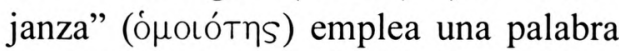

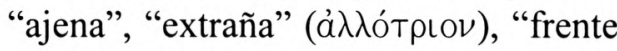
a la palabra propia" (тapà tò kúpıov) o

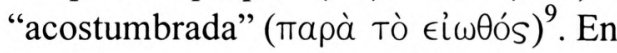
la antigua retórica la metáfora también aparece asociada al símil ( $\epsilon i \kappa \omega ́ v, ~ \epsilon i \kappa a-$ $\sigma i ́ a)$, en la idea de que ambas figuras

Cf. M. Fuhrmann, 1964, pp. 53, 249 s.

Un análisis pormenorizado del tema puede leerse en A. Bravo García, 1973, pp. 141-191. Cf. Plu., Mor. 408b, 469e, 784f, 805a, 814ac, etc.

El impulso agresivo del hombre y su ira, si no es contenida mediante la razón, así como una vida social que le expone al riesgo continuo de conflictos, pueden ser causa de su

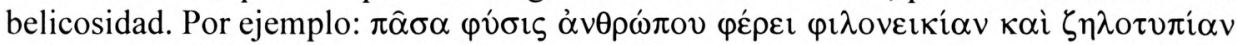

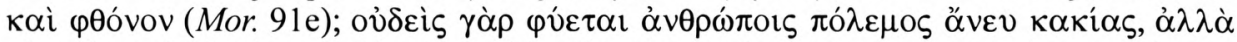

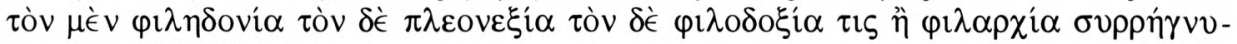
бiv (Mor. 1049d); etc.

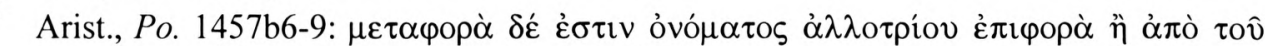

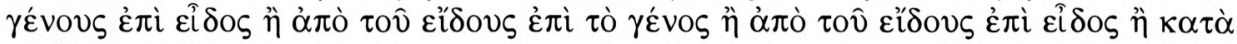

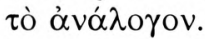

Arist., Po. 1458a23; 1458b3-4. Véase el excelente análisis de A. DíAZ TeJERA, "La metáfora en Aristóteles. Poética 21. 1457b7-25”, en J. A. LóPEz FÉrez (ed.), De Homero a Libanio, Madrid, 1995, pp. 301-316. 
sólo difieren por la ausencia o presencia del nexo comparativo ${ }^{10}$; pero a diferencia del símil, donde la imagen mantiene su significado pleno, la metáfora entraña un deslizamiento de significado producto de la interacción o intersección semántica entre ambos términos ${ }^{11} \mathrm{o}$, si se prefiere, de la proyección de algunos rasgos de un concepto sobre otro ${ }^{12}$. El uso apropiado de la metáfora, que Aristóteles tanto encarece ${ }^{13}$, viene determinado ante todo por la adecuación de la analogía subyacente, de tal modo que su integración resulte armónica en un contexto semántico precisamente extraño. En este sentido conviene recordar la importancia que la semejanza y la desemejanza adquieren dentro del pensamiento plutarqueo, como en gran parte de la tradición filosófica griega ${ }^{14}$. En las páginas que siguen trataremos, pues, de analizar las metáforas bélicas

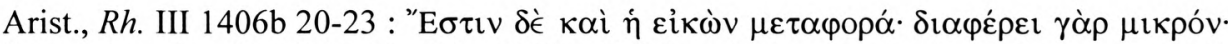

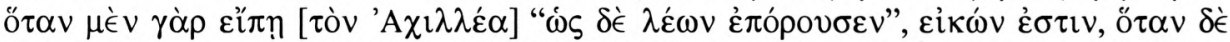

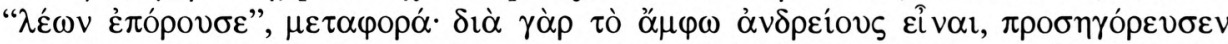

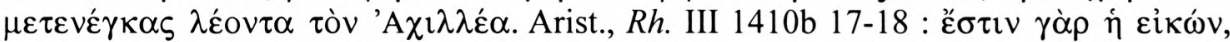

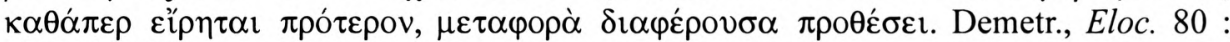

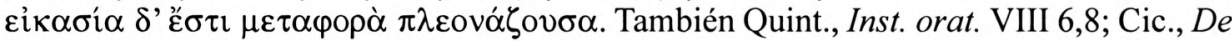
orat. III 39, 157. Cf. M.H. Mccall Jr., Ancient rhetorical Theories of Simile and Comparison, Cambridge (Mass.), 1969, p. 30 ss.; I. TAMBA-Mecz \& P. Veyne, "Metaphora et comparaison selon Aristote", REG 92 (1979), 77-98.

El autor de la Rhet. ad Her. (13, 34, 45-48) marca una importante distinción al clasificar la metáfora entre las verborum exornationes y el símil entre las sententiarum exornationes. También es interesante en este sentido la definición de Hermógenes (SPENGEL, Rhet.

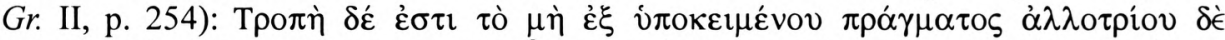

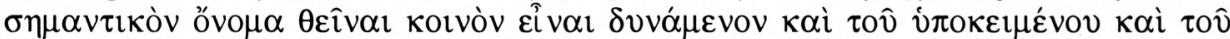

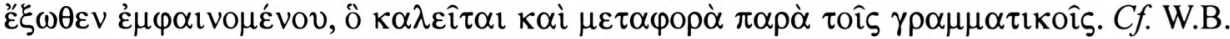
STANFORD, Greek Metaphor. Studies in Theory and Practice, Oxford, 1936, pp. 14 ss., 29-30, 86 ss.; M. LE GUERN, La metáfora y la metonimia, Madrid, 1978, pp. 60-75. Perspective, Berlin-New York, 2000, p. 2 ss., con bibliografia.

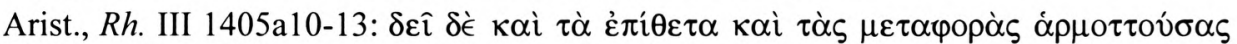

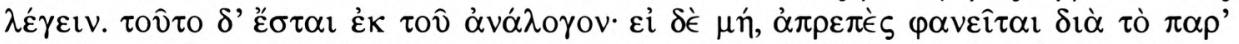

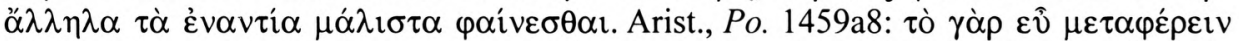

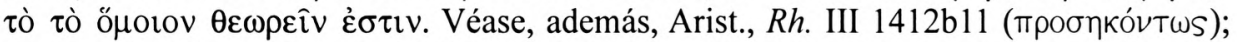

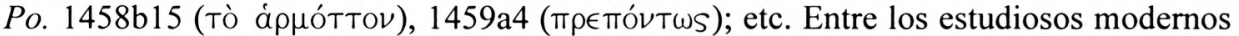
ha subrayado el papel de la semejanza P. Ricoeur, La metáfora viva, Madrid, 1980, pp. 237-291. A propósito de Plutarco, $c f$. R. HiRSCH-LuIPOLD, 2002, pp. 120-122; M. VALVERDE, 1999, pp.

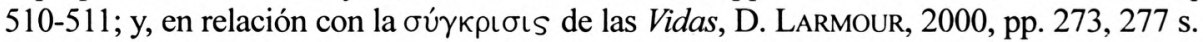


presentes en el Erótico, atendiendo especialmente a la técnica de integración textual así como a su significado en el contexto general del diálogo.

\section{La apacibilidad del diálogo}

Para el desarrollo del diálogo filosófico Plutarco busca un ambiente apacible y sereno. Los personajes reunidos en Tespias pasan el tiempo "filosofando

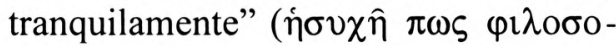

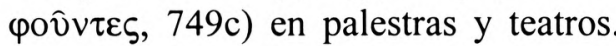
Luego deciden retirarse a un lugar apartado (el santuario de las Musas al pie del Helicón) para escapar del tumulto que vive la ciudad durante la celebra-

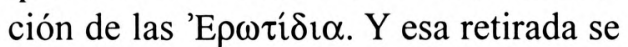
presenta como una suerte de 'repliegue militar' mediante el empleo de un símil y de metáforas del lenguaje bélico:

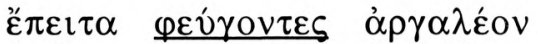

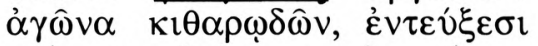

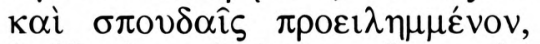

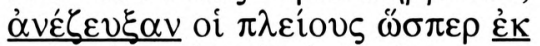

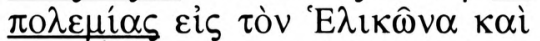

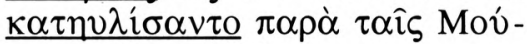

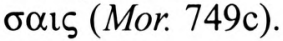

Según el procedimiento de las llamadas "metáforas difusas" 15 , la imagen evocada en el símil

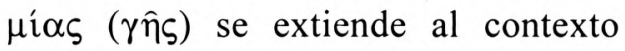

mediante la incorporación de dos verbos específicos del lenguaje militar. El prime-

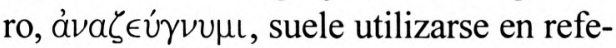
rencia a un ejército con el significado de "levantar el campo", "replegarse", como en la expresión paralela de Mor. 191a

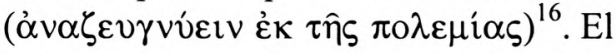

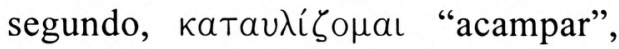
también se aplica al ejército y es frecuente en Plutarco ${ }^{17}$. En cuanto a la expresión $\varphi \varepsilon v ́ \gamma o v \tau \varepsilon \varsigma$... $\alpha \hat{\gamma} \hat{\omega} v \alpha$ mantiene un doble valor: en sentido propio alude a los certámenes musicales celebrados en las fiestas, pero a nivel connotativo se halla en congruencia semántica con la imagen de la 'huida' ante un 'enfrentamiento' bélico. Además, en el pasaje se adivina, como luego en 755a-b (’̉ $v$

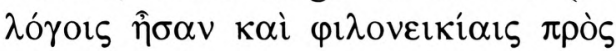
$\dot{\alpha} \lambda \lambda \dot{\eta} \lambda$ ovৎ), una velada alusión al carácter litigioso de los tespieos, que era proverbial en la Antigüedad ${ }^{18}$.

La posterior llegada de Antemión y Pisias, cuya implicación afectiva en el caso de Bacón e Ismenodora les ha llevado a una disensión cada vez más exa-

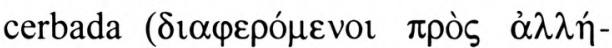

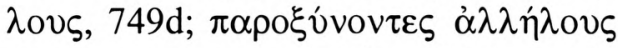

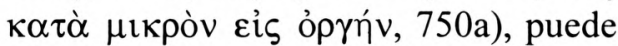
amenazar el equilibrio de la reunión. De modo que el contencioso es remitido al

17 Cf. E., Rh. 518; X., An. VII 5, 15; Plb., V 8, 8; Plu., Publ. 22.2; Pyrrh. 27.3; Lys. 29.5; Alex. 24.13; etc.

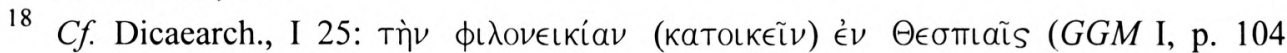
MÜLLER); Ael., $V H$ 11.6. 
arbitraje de Plutarco y sus amigos

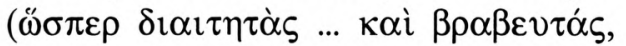
750a) justamente para mantener la apacibilidad del diálogo. Pero la vehemencia de Pisias en defensa de la pederastia, secundada por Protógenes, su actitud

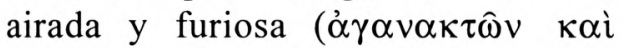

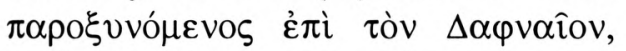
$752 b$ ), su desmesura en el razonamien-

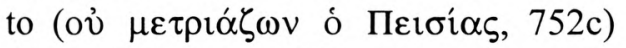
desequilibran el diálogo y provocan la desaprobación de Plutarco (752c-e, 753b-c). Finalmente la noticia del rapto de Bacón por Ismenodora desencadena una reacción airada de Pisias (755b-c) y su consiguiente marcha junto con Protógenes, que "por un lado comparte su indignación y por otro desea calmarlo" ( $\tau \grave{\alpha} \mu \grave{\epsilon} v \sigma v v \alpha \gamma \alpha v \alpha \kappa \tau \hat{\omega} \nu \tau \dot{\alpha} \delta \dot{\epsilon} \pi \rho \alpha \hat{v}-$

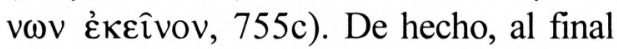
del diálogo sabemos que el personaje ha depuesto su 'aspereza' ( $\chi \alpha \lambda \varepsilon \pi$ ós, $771 \mathrm{~d})$.

En efecto, la historia de Bacón e Ismenodora, que sirve de pretexto para el diálogo, sitúa el debate sobre el amor en el plano de los sentimientos particulares de algunos personajes. En la primera parte la discusión del tema se mueve entre consideraciones generales (caps. 3-6) y opiniones sobre la historia particular (caps. 7-9), como advierten varios personajes $(752 \mathrm{e}, 753 \mathrm{~b}-\mathrm{c}, 755 \mathrm{f})$, hasta que la salida de los implicados afectivamente en el caso, en particular de Pisias (755c), seguido de Protógenes, y luego de Antemión (756a), permite que la reunión recupere un tono apacible y el diálogo se eleve al plano de la reflexión general ${ }^{19}$. Se trata de un procedimiento habitual en la construcción del diálogo plutarqueo: cuando la discusión alcanza un tono demasiado agrio y polémico, Plutarco aparta de la escena a los personajes que por una actitud colérica o un carácter belicoso ponen en peligro su

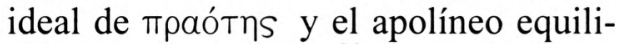
brio del $\mu \eta \delta \dot{\nu} \nu$ ä $\gamma a \nu{ }^{20}$. En este sentido resulta esclarecedor un significativo pasaje del De profectibus in virtute, donde Plutarco, al subrayar la conveniencia de un uso provechoso $(\chi \rho \eta \sigma \tau \imath-$ $\kappa \hat{\omega} \varsigma)$ del discurso en la conversación

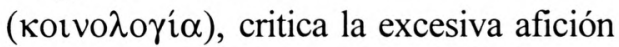
por disputas y pendencias en el diálogo de investigación equiparando la agresividad dialéctica con un combate de boxeo ${ }^{21}$.

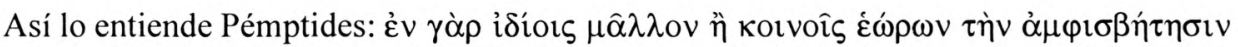

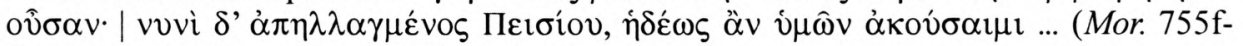
756a). $C f$. R. FlacEliÈre, 1980, p. 5.

Así procede con Glauco en Tuend. san. 122b-c (personaje calificado de $\varphi \imath \lambda o \mu \alpha \chi \hat{\omega} v$,

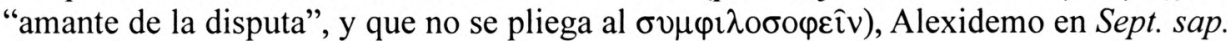
conv. 148e-149b, Dídimo en Def. orac. 413a-d, el Epicúreo en Ser. num. vind. 548a-b, Heraclides en Suav. viv. Epic. 1086e-f. Cf. K. ZIEGLER, Plutarco, trad. ital. M. R. ZANCAN RinAldini, Brescia, 1965, p. 302; L. VAN DER STOCKT, 2000, pp. 108-112.

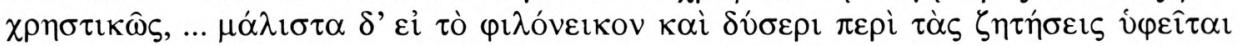




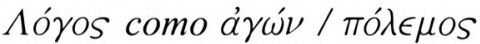

El uso metafórico de léxico de la guerra, o de las competiciones deportivas, para describir una disputa verbal es frecuente en diversos géneros literarios griegos, como la comedia, la oratoria o

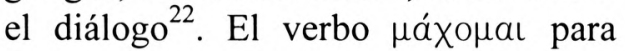
designar metafóricamente un combate dialéctico aparece ya desde Homero y es frecuente en Platón ${ }^{23}$; también el

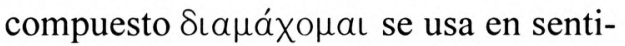
do figurado a propósito de una lucha dialéctica ${ }^{24}$. Asimismo el verbo $\pi 0 \lambda \epsilon$ $\mu \epsilon ́ \omega$ expresa de manera metafórica la oposición a una persona u opinión ${ }^{25}$. En algunos casos el empleo de estos térmi- nos se ha generalizado tanto en contextos semánticos diversos que se han covertido en metáforas banales. Por ejemplo, el grupo léxico de ả $\gamma \omega \dot{\omega} v$ con sus compuestos y derivados ( $\dot{\alpha} \gamma \omega v i \zeta{ }^{\circ}-$ $\mu a \mathrm{l}, \dot{\alpha} \gamma \omega \nu$ LTTńs, etc.), originario de los certámenes atléticos, designa a menudo un enfrentamiento bélico ${ }^{26}$ y también un debate dialéctico, muy característico en el caso de la comedia antigua ${ }^{27}$, así como en el diálogo y en la controversia retórica de base sofística ${ }^{28}$.

El argumento del Amatorius parte de la comparación ( $\sigma u ́ \gamma \kappa \rho \iota \sigma \iota s)$ entre pederastia y amor heterosexual. El coloquio se presenta en principio como un $\alpha \gamma \omega \dot{\omega} v$

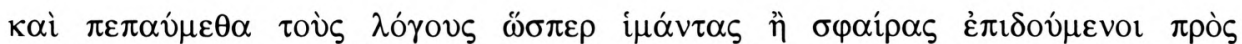

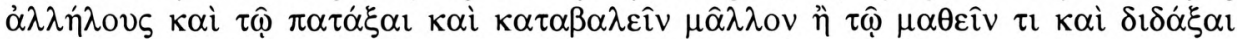

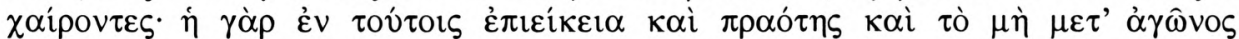

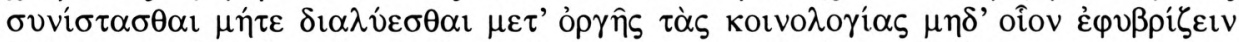

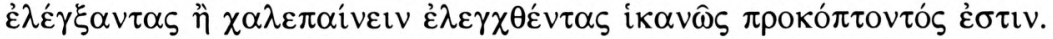

Cf. J. Taillardat, Les images d'Aristophane, Paris, 1965, pp. 335-341; P. LouIs, 1945, pp. 57-63.

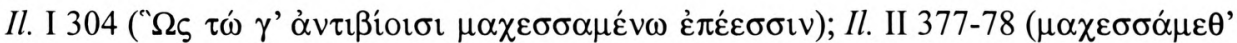

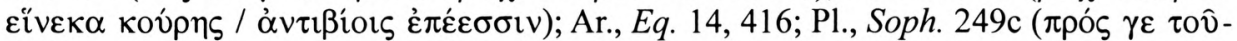

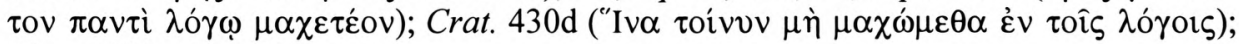
Theet. 205a; R. 342d; etc.

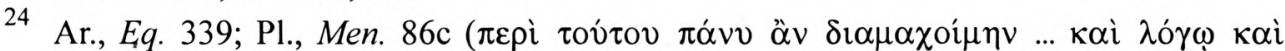

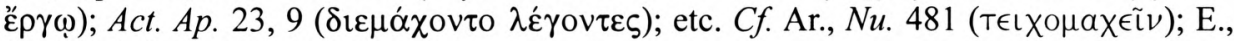

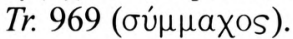

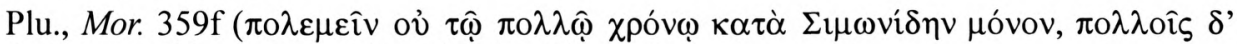

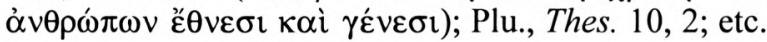

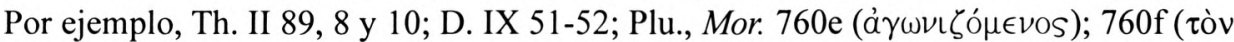
$\dot{\alpha} \gamma \hat{\omega} \vee \alpha)$; etc.

27 Ar., Ach. 392, 481; Eq. 614, 688; Nu. 958; V. 533; Ra. 794, 867; etc. Para la tragedia, $c f$. E., Supp. 427; Io. 939.

Pl., Smp. 194a; Hp. Mi. 369c. En el Protágoras (335a) platónico el sofista declara que al

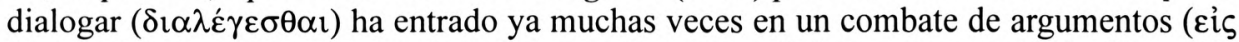
$\left.\dot{\alpha} \gamma \hat{\omega} v \alpha \lambda{ }^{\circ} \gamma \omega v\right)$. A propósito de los $\lambda o ́ \gamma \omega \nu$ ả $\gamma \tilde{\omega} v \in S$ sofísticos, véase también Gorg., 82 B 11, 13 DK; Protag., 80 A 1 p. 254, 2 DK (D.L., IX 52); Pl., Hp. Mi. 364a. 
entre partidarios de una y otra forma de Łp $\rho \omega s$, una lucha dialéctica que Plutarco describe evocando la imagen de la gue-

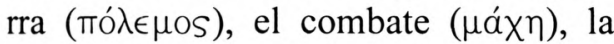
disputa ( $\nu \in \tilde{I} \kappa O S)$ y las armas (öா $\pi \lambda \alpha$ ). En efecto, como luego advierte Pémptides, se trata de una "discusión" o "contro-

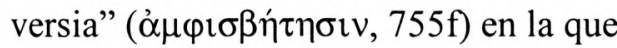
unos pretenden asociar el Amor con la relación pederástica y otros con la rela-

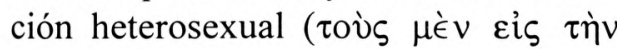

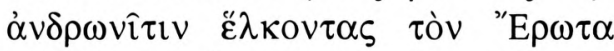

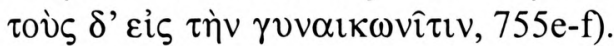
Entre los que se oponen al matrimonio de Bacón e Ismenodora ( $\underline{\alpha} v \tau \alpha \gamma \omega v i \sigma \tau \alpha i$

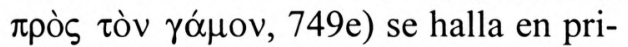
mer lugar su amante Pisias y también Protógenes, a quien Dafneo acusa irónicamente de haber venido "para hacer la

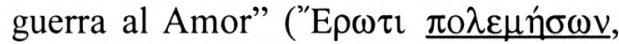
750a). En su réplica Protógenes manifiesta que su intención no es "combatir al

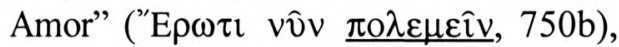
sino precisamente "luchar en defensa

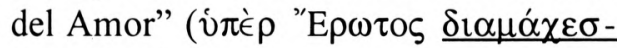
$\underline{\theta \alpha \mathrm{l}}, 750 \mathrm{~b})$ que considera genuino. Mas de nuevo Dafneo atribuye su rechazo del amor por las mujeres a un "afán de querella" ( actitud y las palabras desmedidas de Pisias suscitan a su vez la primera reacción de Plutarco y le "hacen armarse" ( $\left.\dot{\varepsilon}^{\prime} \xi_{0} \pi \lambda \hat{i} \zeta \varepsilon 1,752 \mathrm{c}\right)$ en defensa del amor conyugal, según expresión tomada de un autor trágico desconocido ${ }^{30}$. Tras dos nuevas intervenciones de Pisias y Protógenes, Antemión incita a Plutarco, como si pronunciara el katakeleusmós de un agón de comedia, a 'defender' $(\underline{\alpha} \mu \nu v \varepsilon, 753 c)^{31}$ el amor frente a aque-

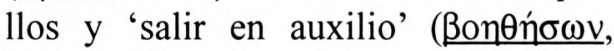
$753 \mathrm{c}$ ) de la riqueza. El cruce de réplicas entre ambos bandos se presenta asimismo como un intercambio de 'golpes' dialécticos merced al empleo de dos compuestos de $\kappa \rho o u ́ \omega$, que subrayan la brusca interrupción de Dafneo a Protógenes ( $\alpha \nu \tau t$ -

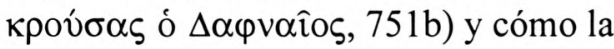
posición extrema de Pisias choca inclu-

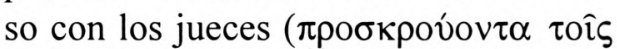
$\delta \imath \kappa \alpha \sigma \tau \alpha \hat{\imath} \varsigma, 752 \mathrm{de})^{32}$.

La segunda parte del diálogo (756a766d) constituye una apoteosis de Eros en réplica a la intervención de Pémptides (755e-756a). Y en la tercera parte $(766 \mathrm{~d}-771 \mathrm{c})$ la contraposición entre ambas formas de $\epsilon$ $\rho \omega s$ se materia-

En Quaest. conv. 736e, por ejemplo, el simposio es escenario de "competición y rivali-

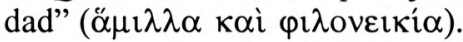
Fr. adesp. 404 NAUCK = KANNICHT-SNELL.

1 La forma ŏ $\mu v v \varepsilon$ es una corrección de Wyttenbach frente al transmitido ỏ $\mu v ́ v \varepsilon 1$.

32 El grupo léxico de кроúw, habitual en el lenguaje de la lucha y el boxeo, se emplea con frecuencia en contextos bélicos y puede aludir también a los "golpes" de un enfrentamiento de discursos al estilo de la retórica sofística. Cf. Pl., Tht. 154d-e ( $\sigma v v \varepsilon \lambda \theta o ́ v \tau \varepsilon \varsigma$

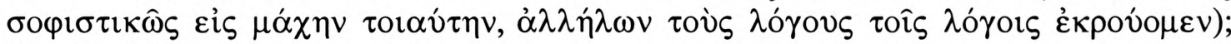
Ar., Eq. 1379, Nu. 318. 
liza más bien dentro del propio discurso de Plutarco. Así, una vez demostrada la igualdad de los sexos, el discurso de Plutarco se dirige contra los que niegan el amor identificándolo con un mero deseo $\mathrm{y}$, en su réplica a una supuesta intervención de Zeuxipo, evoca de nuevo metafóricamente la imagen del "combate":

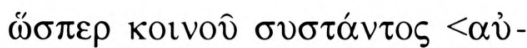

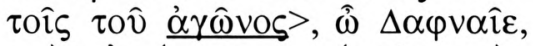

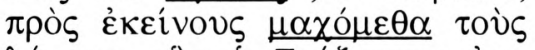

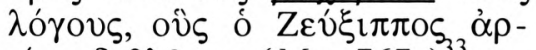

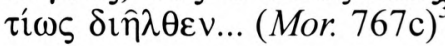

Esta imagen del enfrentamiento verbal como una lucha se refleja también en el nivel de la argumentación discursiva a propósito de las autoridades citadas o aducidas. Así, en relación con la divinidad de Eros, Plutarco recuerda que poetas, legisladores y filósofos discrepan entre sí acerca de los dioses

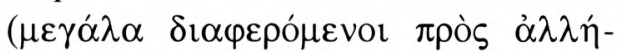
$\lambda$ ovs, 763c); y los filósofos, por ejemplo, en muchos casos "polemizan"

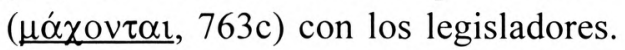
En todo el pasaje se insiste sobre la discordancia entre esas tres facciones

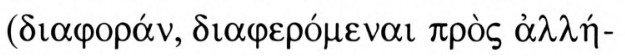

$\lambda \alpha \varsigma, \sigma \tau \alpha \dot{\sigma} \sigma \varepsilon 1 \varsigma, 763 \mathrm{~d}-\mathrm{e})$ y la idea se ilustra por añadidura mediante un símil. Con tal insistencia Plutarco en realidad trata de resaltar por contraste la coincidencia de todos ellos sobre el asunto que más le interesa: la divinidad de Eros.

Por lo demás, el hecho de que Plutarco explote ampliamente en el

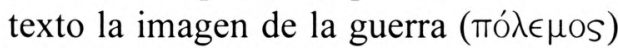
y del combate $(\mu a ́ x \eta)$ aplicada al choque dialéctico, no significa que el $\mathrm{Ama}$ torius pueda considerarse un diálogo de modus o tono "polémico"34. La primera parte del diálogo responde a una forma agonística, ${ }^{35}$ mientras que el resto presenta una forma demostrativa o expositiva con marcado predominio del discurso autorial de Plutarco ${ }^{36}$.

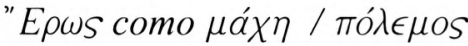

En la tradición literaria griega son comunes las metáforas de la guerra aplicadas al amor en diferentes aspectos. Ambos dominios, el amor y la guerra, también aparecen asociados en el pensamiento plutarqueo, y no sólo en las metáforas. Tanto la pasión amorosa como el ardor guerrero son para Plutar-

El indicativo $\mu \alpha \chi o ́ \mu \varepsilon \theta \alpha$ es la lectura de los mss. La mayoría de los editores, con excepción de Winckelmann, adoptan la corrección $\mu \alpha \chi \omega \dot{\omega} \mu \varepsilon \theta \alpha$ de Amyot y Wyttenbach.

A esa categoría pertenecen: Bruta anim., Comm. not., Suav. viv. Epic., Col. Véase L. VAN DER STOCKT, 2000, pp. 108 s., 116, que clasifica los diálogos plutarqueos en "dialécticos", "didácticos" y "polémicos".

35 Según una clasificación de los diálogos platónicos recogida por Diógenes Laercio (III

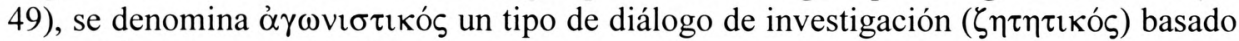
en el enfrentamiento de ideas.

Para todo ello, $c f$. M. VALverde, 2004, (en prensa). 
co dos formas de $\mu$ avía inspirada por un dios (758f-759d). El impulso 'com-

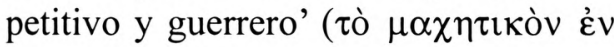

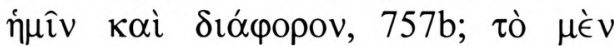

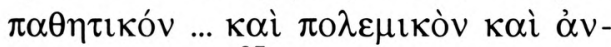
$\tau i \pi \alpha \lambda \circ v, 757 \mathrm{c}^{37} ; \dot{\eta} \pi \mathrm{o} \lambda \varepsilon \mu \mathrm{\iota} \hat{\eta} \mu \alpha v^{\prime} \alpha$,

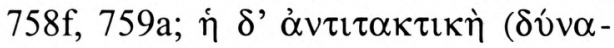
$\mu(\varsigma), 759 \mathrm{e})$, representado por el dios Ares, constituye en realidad la antítesis

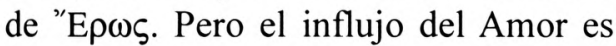
$\tan$ poderoso que le vence y le aventaja incluso en valor ${ }^{38}$ : en la lucha con los

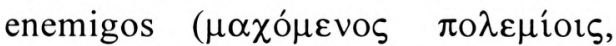

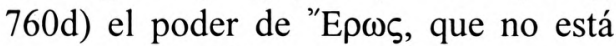

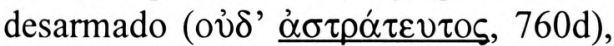
resulta superior al de Ares ${ }^{39}$.
Precisamente en relación con el poder de Eros cita Plutarco el verso 497 de las Traquinias de Sófocles ("con gran fuerza se lleva Cipris la victoria"):

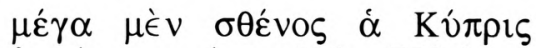

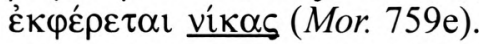

La imagen del Amor invencible, desarrollada en el célebre coro de

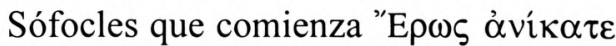
$\mu \alpha ́ \chi \alpha \nu(\text { Ant. 781) })^{40}$, constituye un tópico muy extendido en la literatura grie$\mathrm{ga}^{41}$. En este sentido cabe recordar también que Eros aparece caracterizado con armas habitualmente desde la poesía helenística $^{42}$ y lanzando sus dardos ya

37

38

39

40

41

42

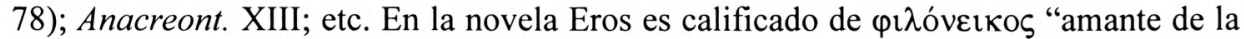
lucha" (Charito I 1, 4; X. Eph., I 2, 1); y se representa a Quéreas herido de amor como un guerrero en el combate (Charito I 1,7 ).

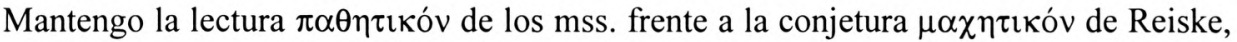
generalmente aceptada por los editores, salvo por WinCKELMANN $(1836$, p. 159) que la desaprueba.

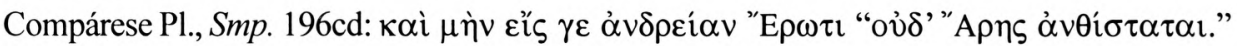

En una serie de ejemplos de personajes míticos e históricos Plutarco muestra la fuerza que Eros infunde a sus poseídos para combatir: el amante es, en efecto, el mejor "aliado

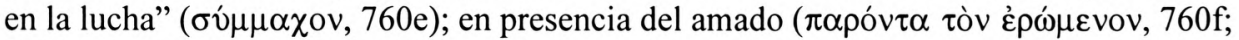

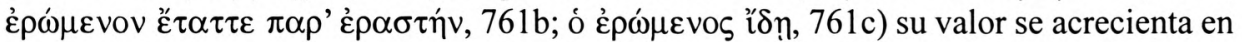
el combate contra los enemigos (

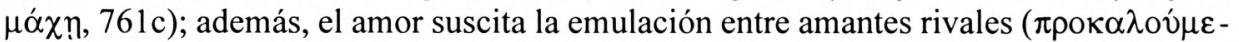

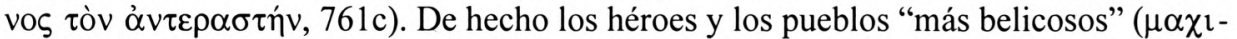

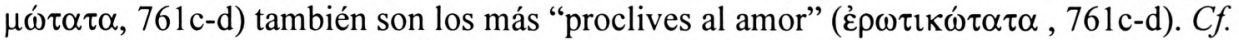
Pl., Smp. 178e-179b; X., Smp. 8, 32-35.

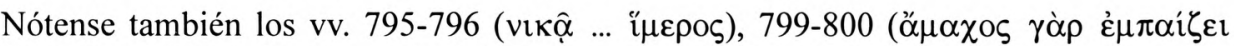
$\theta \varepsilon o ̀ \varsigma ~ ' A \varphi p o \delta i ́ \tau \alpha)$. En el pasaje de Traquinias la metáfora de la "victoria" podría corresponder al ámbito de los agones deportivos, si se relaciona con los versos 441-42 de la

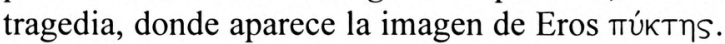

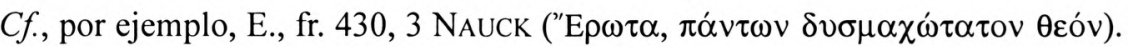

Véase A. R. III 156-157, 278-287; Theocr. XXIII 4-5; Mosch. I 18-21; Mel. (A.P. XII un guerero en el combate (Charito II, 7 ). 
desde Eurípides ${ }^{43}$. Pues bien, la unión de Bacón e Ismenodora representa un claro ejemplo de lo difícil que resulta

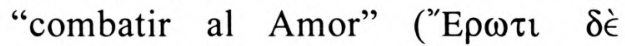

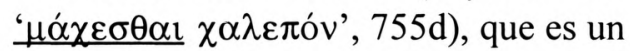
dios de fuerza irrefrenable. Curiosamente el conocido tema de la Seelenkampf o "lucha interior" no es explotado en este caso, pues Ismenodora no trata de combatir su pasión amorosa. La expresión plutarquea juega con una cita de Heráclito ${ }^{44}$, donde se advierte que es

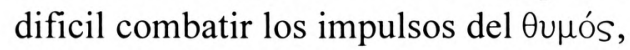
y evoca también pasajes platónicos en

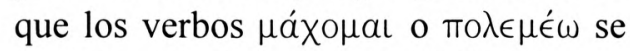
aplican metafóricamente a la lucha contra los deseos o los impulsos ${ }^{45}$.

La proyección del sentimiento amoroso es imaginada en ocasiones como una "lucha" ( $\mu a ́ \times \eta)$ por la 'conquista' del amado. Así aparece ya en Safo, donde la poetisa pide a Afrodita que sea su "aliada en la lucha" ( $\sigma \dot{\mu} \mu \mu \alpha \chi \sigma \varsigma$, fr. $1,28)$ del amor y le procure reciproci- dad de parte de la joven amada. En estrecha relación se halla la imagen del amor como un certamen o competición en pos del ser amado:

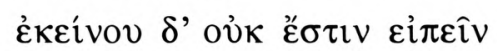

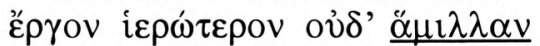

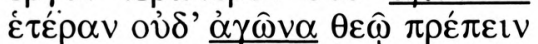

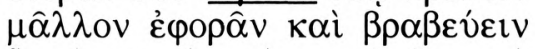

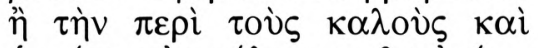

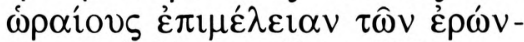

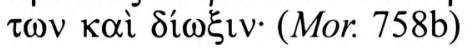

De igual modo que $\alpha \gamma \omega \dot{v} v$, el término $\dddot{\alpha} \mu \imath \lambda \lambda \alpha$, perteneciente al léxico de la competición deportiva $^{46}$, se refiere en este caso a la prueba que entrañan la

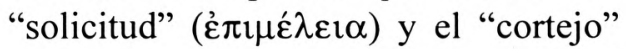

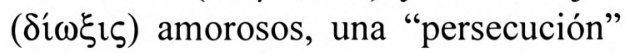
que está en la naturaleza misma del amor según el pensamiento platónico

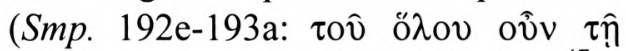

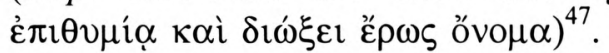

En varios pasajes del Amatorius subyace una equiparación metafórica del amor entre Bacón e Ismenodora con la guerra. En efecto, la relación entre

E., Med. 531; Hipp. 530-532; etc.

Fr. 22 B 85 DK, citado también en Plu., Mor. 457d; Cor. 22, 3.

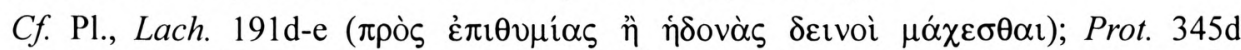

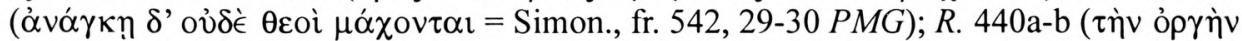

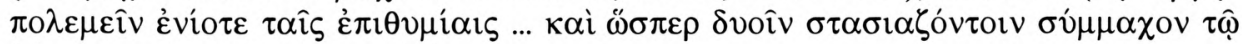

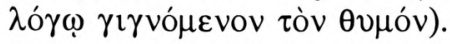

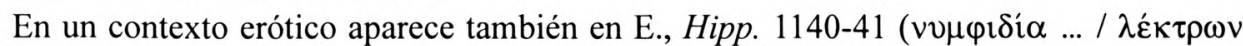

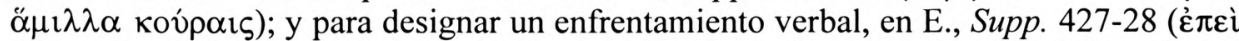

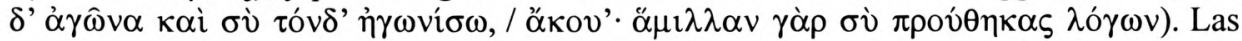
imágenes de los agones deportivos aplicadas al ámbito del amor son frecuentes en la

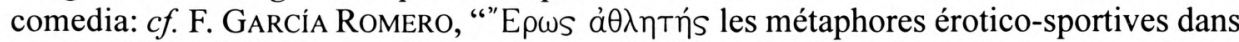
les comédies d'Aristophane", Nikephoros 8 (1995), 57-76.

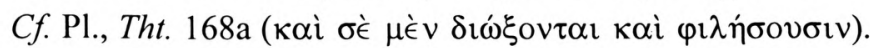


ambos es presentada en el diálogo como conflictiva en un doble sentido: en primer lugar, dentro de la dialéctica entre pederastia y amor conyugal; y en segundo lugar, por la inversión de la situación tradicional (en cuanto a edad, riqueza y posición) entre los dos miembros de la pareja, que se vislumbra por parte de algunos como una amenaza para el equilibrio y la estabilidad conyugal.

De acuerdo con la óptica tradicional el vínculo matrimonial es contemplado en el diálogo como una relación donde el varón debe predominar ( $\dot{\varepsilon} \pi \kappa \rho \alpha \tau \dot{\eta}-$ $\sigma \eta ̣, 752 \mathrm{e})^{48}$. De ahí que el matrimonio de Bacón e Ismenodora resulte un

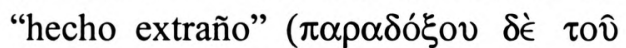
$\pi \rho \alpha ́ \gamma \mu \alpha \tau \circ \varsigma, 749 \mathrm{e})$ por el riesgo que implica la unión del muchacho con una mujer de mayor edad, riqueza y posición $(749 \mathrm{e}, 752 \mathrm{e}, 753 \mathrm{c})$, que parece

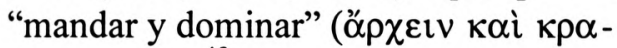
$\tau \varepsilon \hat{\imath} v, 752 \mathrm{e})^{49}$. En todo caso, para Plutarco la relación matrimonial resulta difícil de conciliar. Si la unión sin amor transcurre a menudo como una "lucha

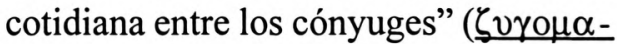

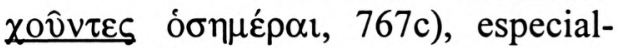
mente difícil resulta la convivencia matrimonial entre jóvenes cuando el amor está presente, sobre todo al principio en tanto no deponen su "orgullo"

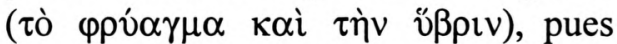

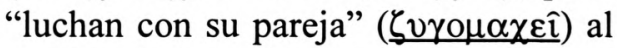
no ser capaces de "mandar" ni querer "obedecer"; así el matrimonio zozobra como un barco sin timonel ${ }^{50}$ :

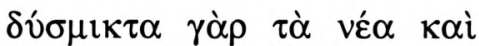

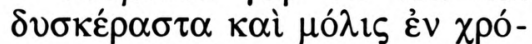

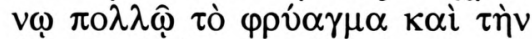

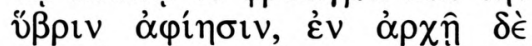

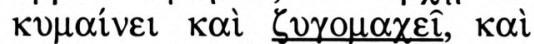

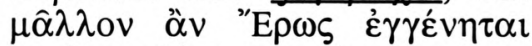

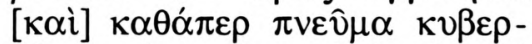
vท́

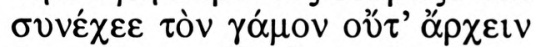

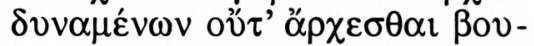
$\lambda \mathrm{o} \mu \varepsilon v \omega \nu$ (Mor. 754c).

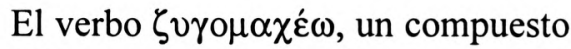
metafórico que se dice de la pugna de un animal con su compañero de yunta ${ }^{51}$

Para los matices de la posición de Plutarco en este tema, $c f$. M. VAlverde, "Amor y matrimonio en el Erótico de Plutarco", en J.M. NiETo (coord.), Lógos Hellenikós. Hom. G. Morocho, vol. I, León, 2003, pp. 441-454.

49 Sin embargo, Plutarco aduce ejemplos de mujeres inferiores, cortesanas y siervas, que

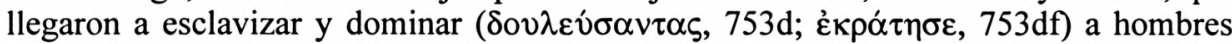
poderosos. Y, de manera inversa, otros hombres desposados con mujeres más ricas e ilus-

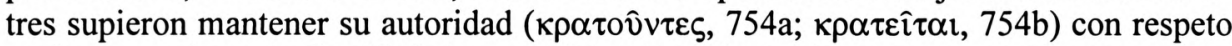
y afecto gracias a la dignidad de su carácter. La misma idea expresa en Coniug. praec. 11 y 33 (Mor. 139c-d, 142d-e).

50 En consecuencia, podría incluso estar bien que Ismenodora vaya a gobernar (

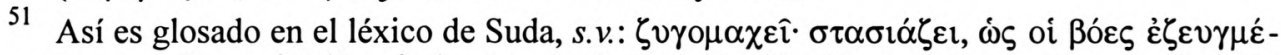

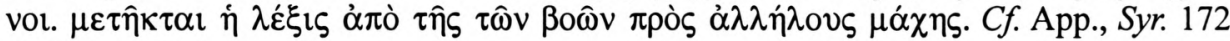


y, por analogía, de la "lucha con familiares o domésticos", puede aplicarse a la disputa entre los cónyuges ${ }^{52}$, como en el presente caso o en Mor. 986a,

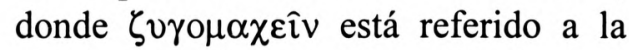
pareja de Ulises y Circe. La imagen evocada en la metáfora verbal queda reforzada en el contexto por la presencia de $\varphi \rho v \alpha \gamma \mu \alpha$, que propiamente significa "relincho" (así en 754a) y en sentido figurado denota "orgullo", 53 , como refleja bien su emparejamiento con üßpıs. De modo que el pasaje sin duda evoca también la imagen platónica del amor, narrada en el Fedro (246a-b, 253c-

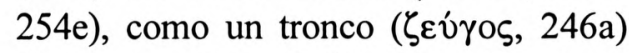
tirado por dos alados corceles, cuya conducción resulta difícil $(\chi \alpha \lambda \varepsilon \pi \grave{\eta} \delta \grave{\eta}$

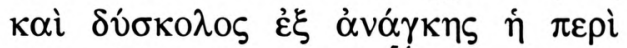

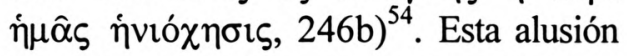
implícita se confirma de modo explícito en otro texto donde Plutarco utiliza el mismo verbo con referencia a la lucha entre los corceles de la biga alada de $\operatorname{Eros}^{55}$.

La unión amorosa entre marido y mujer, que Solón aconsejaba practicar al menos tres veces al mes, sirve en opinión de Plutarco para renovar el matri-

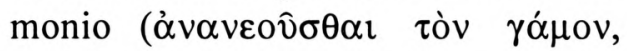
769b) de las mutuas "disensiones" o "enojos" ( $\sigma \chi \imath \sigma \mu \alpha \dot{\alpha} \omega \nu$ / $\delta v \sigma \chi \varepsilon \rho \alpha \sigma \mu \alpha \dot{-}$ $\tau \omega v, 769 \mathrm{~b})^{56}$, igual que las ciudades cada cierto tiempo renuevan sus "pac-

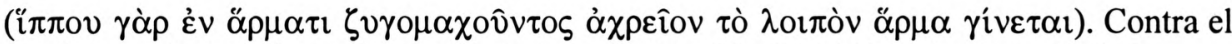
uso inapropiado del vocablo se advierte en Arist., Rh. III 1413a 14 y Luc., Sol. 6.

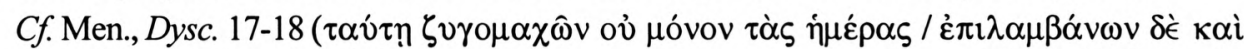

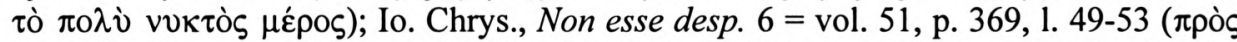

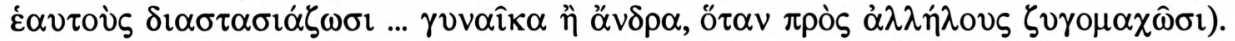

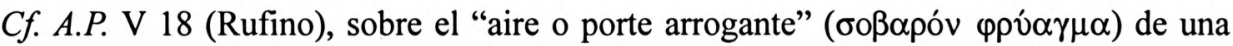
mujer; etc.

El paralelismo con el pasaje plutarqueo es muy estrecho: en la narración del Fedro el

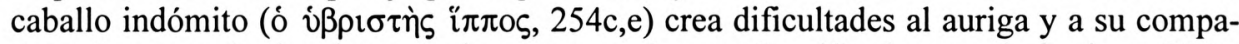

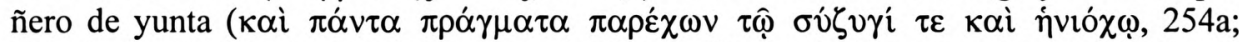

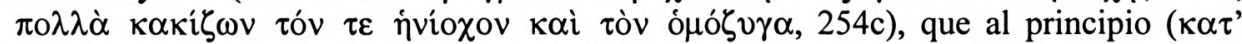

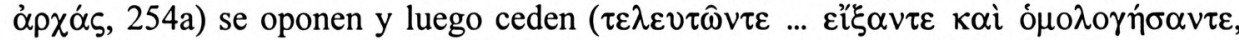

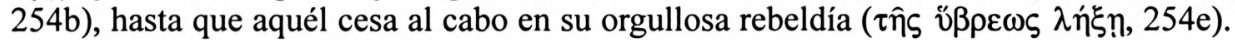

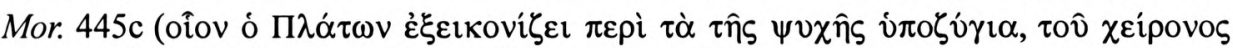

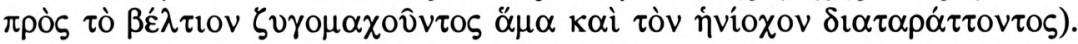

En lugar del transmitido $\sigma \chi \eta \mu \alpha ́ \alpha \omega v$, que no ofrece un sentido satisfactorio en el contex-

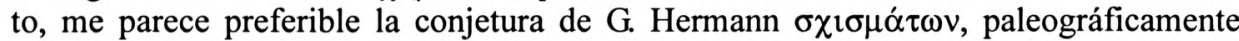
verosímil y semánticamente adecuada; también resulta atractiva en función del contexto (cf. Plu., Sol. 20.4), aunque paleográficamente menos económica, la propuesta $\delta v \sigma-$ $\chi \varepsilon \rho \alpha \sigma \mu \alpha \dot{\tau} \tau \omega \nu$ ("enojos", "disgustos", "displicencias") de Gatakero, aceptada por Winckelmann. En cambio, me parecen menos adecuadas otras propuestas como $\dot{\varepsilon} \gamma \kappa \lambda \eta \mu \alpha \dot{\alpha} \tau \omega \nu$ de

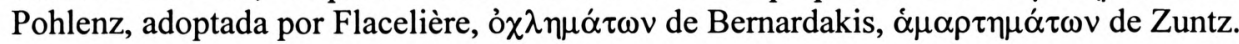




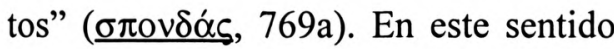
cabe recordar que Plutarco viaja a Tespias recién casado con su esposa para participar en las Erotidias y ofrecer sacrificios a Eros precisamente "con motivo de una disputa y desavenencia

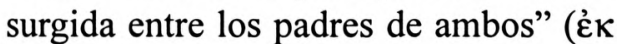

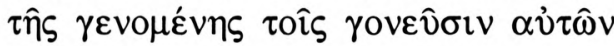

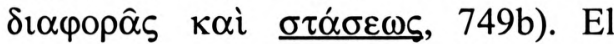

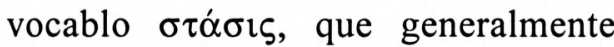
designa una "revuelta" o "lucha civil", objeto de peor valoración que la guerra externa en Plutarco y en todo el pensamiento griego ${ }^{57}$, se refiere en este caso, como otras veces el verbo $\sigma \tau a \sigma l a ́ \zeta \omega$, a las disensiones en el ámbito conyugal ${ }^{58}$.

El rapto de Bacón por Ismenodora y sus amigos se lleva a cabo sin violencia

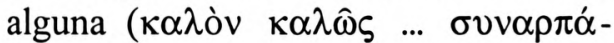
$\sigma \alpha \nu \tau \varepsilon \zeta, 754 f)$, con la complacencia

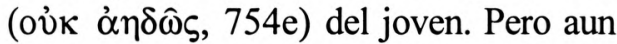
así, por lo que entraña de predominio femenino ( $\gamma \cup \vee \alpha \iota \kappa о \kappa \rho \alpha \tau o v \mu \varepsilon ́ v \eta, 755 \mathrm{c}$ ), resulta "un hecho asombroso lleno de

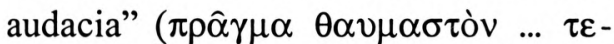

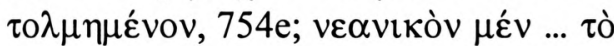

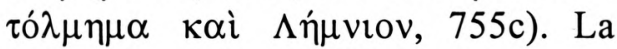

visión metafórica del amor como una guerra adquiere considerable desarrollo en la posterior valoración que Soclaro hace del rapto. En efecto, la intervención del personaje, que habla con cierta ironía, está salpicada de términos pertenecientes al lenguaje bélico:

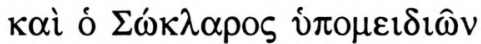

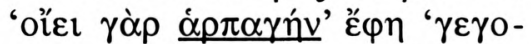

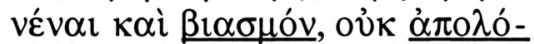

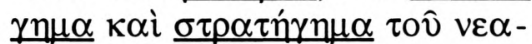

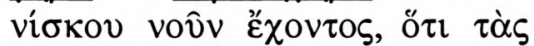

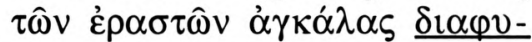

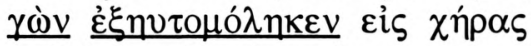

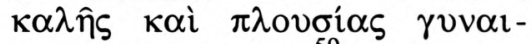
кós'; (Mor. $755 \mathrm{c}-\mathrm{d})^{59}$.

Soclaro descarta que haya podido haber "rapto con violencia" y supone más bien "una estratagema defensiva" por parte del joven, que "ha huido" del bando de sus amantes, que "ha desertado" de la pederastia y "se ha pasado" al amor de una mujer. Entre los vocablos subrayados destaca en particular el uso del verbo $\dot{\varepsilon} \xi \alpha v \tau o \mu \circ \lambda \hat{\varepsilon} \omega$, “desertar”, un término específico del léxico de la gue$\mathrm{rra}^{60}$. Los dos tipos de amor contrapues-

Mor. 824b-c; 232c; Brut. 12, 3; etc. Cf. A. Bravo García, 1973, pp. 174 ss., 181.

Cf. Io. Chrys., Non esse desp. 6 (vol. 51, p. 369), que habla de la discordia entre los espo-

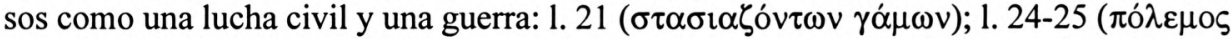

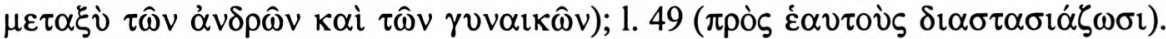

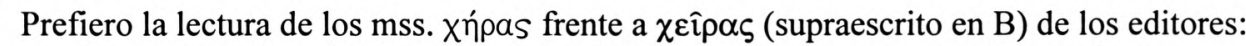

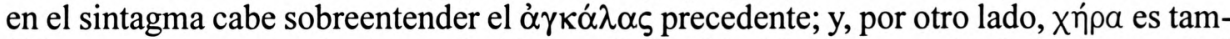

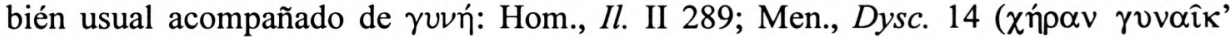
ع̌ $\gamma \eta \mu \varepsilon)$; Plu., Mor. 182b; 472c; etc. $C f$. WinCKELMANN, 1836, p. 145.

$C f$. Aen. Tact., 23, 1; D.C., XLI 4.3. En sentido figurado lo usa ya Ar., $N u$. 1104. El verbo

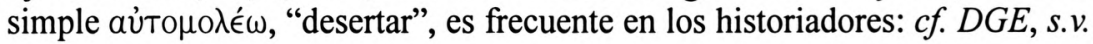


tos en el diálogo, pederastia y amor conyugal, aparecen así figurados como campos enemigos en una batalla. Por lo demás, la solución del conflicto amoroso en virtud de una estratagema recuer-

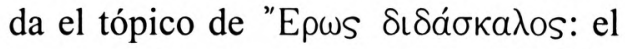
enamorado encuentra por inspiración del dios, como Ismenodora en este caso

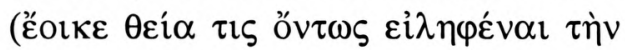

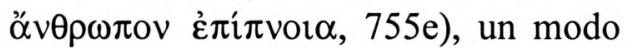
de alcanzar su propósito, ya que el Amor, en palabras de Plutarco mismo, es "el único invencible de los estrate-

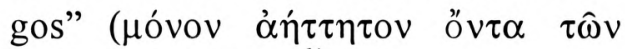
$\underline{\sigma \tau \rho \alpha \tau \eta \gamma \hat{\omega} v}, 761 \mathrm{~b})^{61}$.

La metáfora de la guerra se aplica también a la relación amorosa en otros ejemplos aducidos por Plutarco en el diálogo. Así ocurre en la anécdota del romano Gaba que, teniendo a Mecenas invitado en su casa, veía a éste "insinuarse" con señas a su mujer:

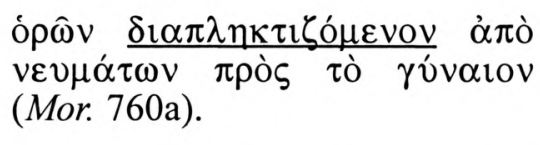

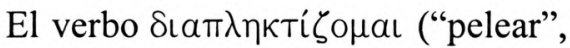
"lanzar un ataque o escaramuza"), que puede usarse tanto en sentido militar como figurado ${ }^{62}$, se aplica en este caso metafóricamente a un "ataque" o "escaramuza" destinado a la conquista amo- rosa; y con idéntico valor aparece en Tim. 14, 3, en un contexto también erótico $(\delta i \alpha \pi \lambda \eta \kappa \tau \iota \zeta o ́ \mu \varepsilon v o v ~ \varepsilon ̉ v ~ \mu \varepsilon ́ \sigma \omega ~ \tau o \hat{\varsigma} \varsigma$

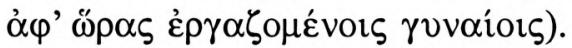

Un aspecto de la relación erótica susceptible de evocación mediante la imagen de la guerra es la rivalidad entre amantes y su disputa por el ser amado, un tema que es aludido con humor a propósito de Ismenodora y sus rivales ( $\tau \hat{\omega} \nu \dot{\alpha} \nu \tau \varepsilon \rho \alpha \sigma \tau \hat{\omega} \nu, 754 c)$ en el amor de Bacón. Muchos amantes rivalizaron ( $\alpha \nu \tau \varepsilon \rho \hat{\omega} \nu \tau \varepsilon \varsigma, 760 b)$ con hombres poderosos hasta el punto de arriesgar la vida

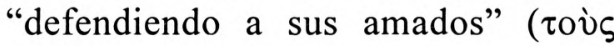

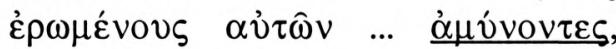
760c). La cretense Gorgo, de la que se enamoró Asandro, era "muy disputada" ( $\underline{\varepsilon \rho \mu \mu \alpha ́ \alpha} \chi \eta \tau \nu, 766 \mathrm{~d})$, pues con él concurrían muchos amantes rivales

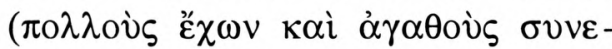
$\rho \hat{\omega} \nu \tau \alpha \varsigma \alpha \hat{v} \tau \hat{\omega}, 766 \mathrm{~d})$. También la cortesana Lais era amada por muchos ( $\left.\pi \circ \lambda v \eta \dot{p} \rho \alpha \sigma^{\circ}\right)$ ), tanto que era "objeto de

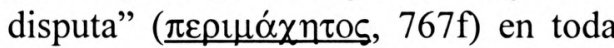
Grecia y el número de sus amantes

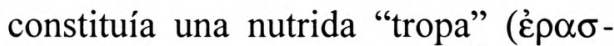
$\left.\tau \hat{\omega} v \ldots \mu \varepsilon^{\prime} \gamma \alpha \nu \underline{\sigma \tau \rho \alpha \tau o ́} v, 767 f\right)^{63}$. En este caso cabe notar de nuevo cómo el tér-

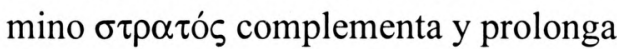
en el contexto la imagen guerrera evo-

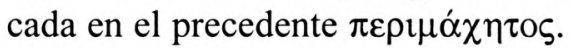

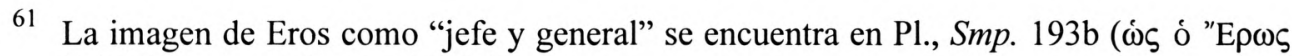

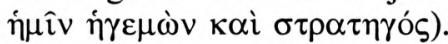

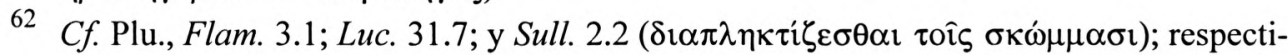
vamente.

63 En Plu., Per. 12.6, $\sigma \tau \rho \alpha ́ \tau \varepsilon v \mu \alpha$ se aplica al colectivo de obreros de un oficio. 
La pederastia en Grecia representa normalmente una condición transitoria en la vida del amado, centrada en torno

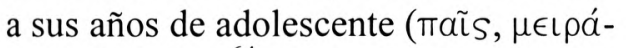

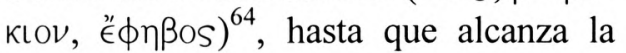
madurez adulta y puede acceder a las metas existenciales que ésta conlleva, el matrimonio entre ellas. Entonces el amante deberá dirigir sus atenciones y afectos a otro joven ${ }^{65}$. Esa condición transitoria de la relación homoerótica, la provisionalidad e inconstancia del amor en la pederastia, es ilustrada en el texto plutarqueo mediante la imagen de los nómadas, que pronto "levantan el campamento como de territorio enemigo":

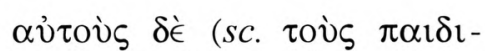

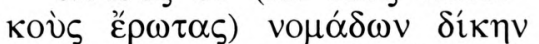

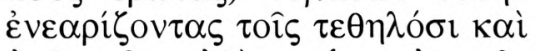

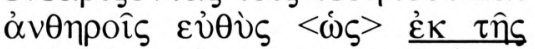

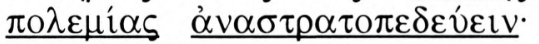
(Mor. 770b).

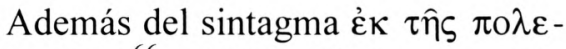
$\mu i \alpha \varsigma(\gamma \hat{\eta} \varsigma)^{66}$, el verbo $\alpha \dot{\alpha} \alpha \sigma \tau \rho \alpha \tau o \pi \varepsilon-$ $\delta \varepsilon v ́ \omega$ ("levantar el campo" un ejército), perteneciente al léxico militar ${ }^{67}$, amplía en el contexto la imagen evocada en el símil. Así pues, el amado ('€ $\rho \omega ́ \mu \in \mathcal{V} O S)$,

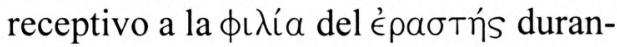
te su etapa de muchacho o de efebo, se torna campo enemigo y hostil apenas accede a la edad adulta.

\section{Los dos frentes de batalla}

Los dos planos en que se mueve el diálogo, la relación entre Bacón e Ismenodora por un lado y el coloquio entre Plutarco y sus amigos por otro, vienen a representar los dos frentes en que se libra la batalla del amor: el plano de las acciones ( $\pi \rho a ́ \xi \in t S)$ y el plano dialéctico $\left(\lambda \text { ć }_{\mathrm{O}}\right)^{68}$. Este doble nivel requiere la entrada en escena de sucesivos mensajeros que informan a los interlocutores del diálogo, retirados al pie del Helicón, sobre la evolución de los acontecimientos en la ciudad en el caso de Bacón e Ismenodora. Así, cuando la viuda, con la colaboración de un grupo de amigos, ha raptado al joven en un audaz golpe de mano, se nos informa del hecho mediante un heraldo que

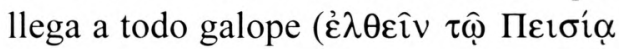

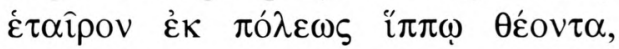

Cf. F. Buffière, Eros adolescent. La pédérastie dans la Grèce antique, Paris, 1980, pp. 605-613. Recuérdese que las dudas de Bacón se deben precisamente a la adecuación de

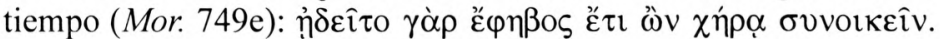

66 Cf. Pl., Phdr. 240a; Plu., Mor. 749f.

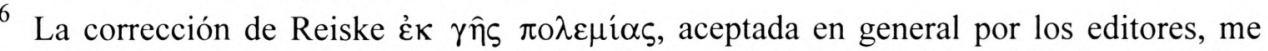
parece innecesaria, pues el giro elíptico tiene paralelos en Plutarco: $\dot{\varepsilon} \kappa \tau \hat{\eta} \varsigma \pi \mathrm{o} \lambda \varepsilon \mu i \alpha \varsigma$

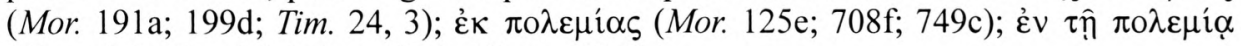
(Cam. 2.8; Tim. 30.1; Luc. 33.4; Cleom. 12.3).

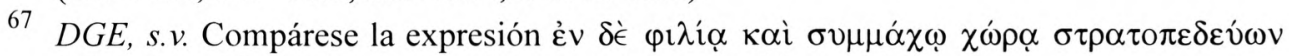
(Plu., Mor. 187a), donde el verbo es usado en sentido propio.

68

Sobre este aspecto, $c f$. M. VALVERDE, 2004, (en prensa). 
$754 \mathrm{e}$ ), con la urgencia propia de quien viniese del frente de batalla:

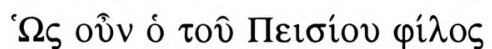

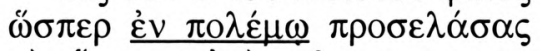

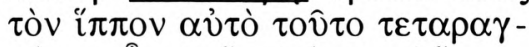

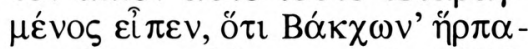

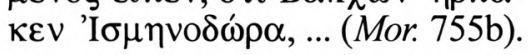

Al final del diálogo asistimos a una escena similar, cuando de nuevo un amigo de Pisias llega con premura

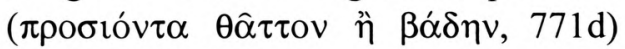
desde la ciudad para anunciar que ya se celebra el matrimonio de Bacón e Ismenodora. Soclaro entonces exclama, no sin ironía: " $¡$ No será precisamente la guerra, Diógenes, lo que anuncias!"

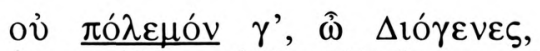
$\dot{\alpha} \pi \alpha \gamma \gamma \dot{\varepsilon} \lambda \lambda \omega \omega \nu$ (Mor. 771d).

La expresión, que es un proverbio tradicional y se halla en el Fedro platónico

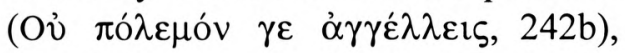
responde al recurso de la antífrasis, una forma de ironía donde el término $\pi$ ó $\lambda \varepsilon$ $\mu \mathrm{s}$, metáfora de una 'mala noticia', se dice para significar lo contrario.

Las peculiaridades del caso han creado tensión entre los contrarios al matrimonio y rivales de Ismenodora, Pisias en particular. El rapto de Bacón provoca también una atmósfera de enfrentamiento en la ciudad (oi $\mu \grave{e} v$

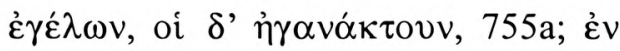

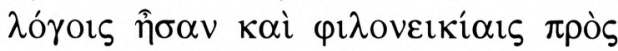
$\dot{\alpha} \lambda \lambda \dot{\eta} \lambda$ ov, $755 b)$ y ocasiona incluso la discrepancia entre los gimnasiarcos

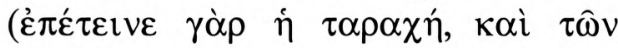

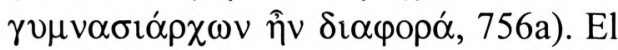
Amor promueve 'querellas', como cantaba el célebre coro de Antígona ${ }^{69}$. La expectación que antes despertaban los certámenes festivos, cuyo ambiente

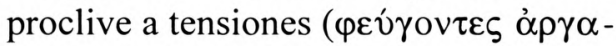
$\lambda \varepsilon \varepsilon^{\prime} \sigma \quad \dot{\alpha} \gamma \hat{\omega} v \alpha \kappa$

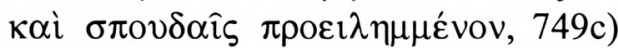
quisieron evitar Plutarco y sus amigos, es acaparada luego por el inaudito rumbo del caso (755a-b). El dramatis-

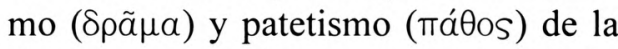
situación, anunciados ya por Autobulo antes de comenzar la narración (749a), el riesgo de que pueda desencadenarse un conflicto abierto, son presentados en el diálogo con distanciamiento e ironía. El alejamiento de la ciudad por parte de los personajes del diálogo es también en cierto modo una metáfora del distanciamiento intelectual necesario para afrontar una reflexión serena sobre el tema. Tanto la narración de la historia como la conversación en torno a su conveniencia están salpicadas con toques de fino humor $^{70}$. Si las imágenes en general, símiles o metáforas, proporcionan al

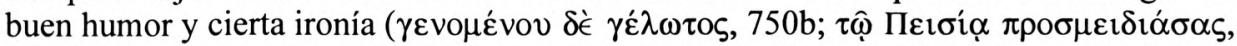

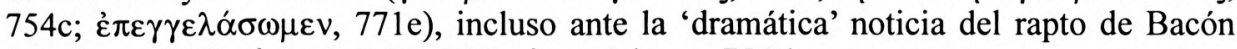

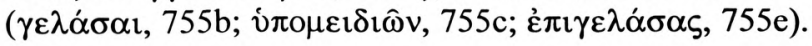


texto relieve y énfasis, en este caso las metáforas de la guerra acentúan el patetismo y la solemnidad desde una clave irónica, como para desdramatizar desde la distancia el dramático acontecimiento.

La prosa plutarquea muestra un acentuado gusto por el recurso de la metáfora, rasgo que también caracteriza el estilo de su admirado maestro Platón. Buena parte de las metáforas bélicas presentes en el Erótico pertenecen al uso común de la lengua griega o se hallan bastante generalizadas en el caudal de la tradición literaria (de hecho, algunas se incorporan al texto a través de las numerosas citas ${ }^{71}$ que Plutarco gusta de rememorar), de modo que pueden resultar más o menos banales. En las metáforas desgastadas por el uso la percepción de la imagen asociada se atenúa, pero tal efecto se contrarresta en el texto plutarqueo por la continuada presencia de metáforas evocadoras de una misma imagen. $\mathrm{Si}$ las metáforas bélicas analizadas no ofrecen gran novedad ni en cuanto al léxico ni en cuanto a los motivos representados, la originalidad de Plutarco reside en la adecuación y funcionalidad de las imágenes dentro del texto.

Plutarco maneja con maestría el arte de las imágenes, la "oportunidad de la

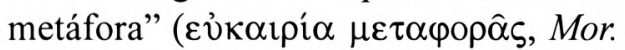
16b) según su propia expresión, basada en una perfecta motivación e integración en el contexto. El empleo de metáforas difusas así como de términos con doble valor, propio y figurado, multiplica los puntos de analogía entre la imagen evocada y el contexto, favoreciendo su pertinencia semántica. Las metáforas constituyen así un valioso recurso para poner de relieve determinados aspectos del pensamiento. Para Plutarco la metáfora, además de un adorno estético (oîs ò $\lambda$ óyos

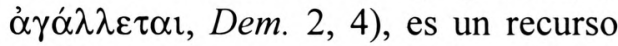
estilístico que proporciona "énfasis" ( $" \mu \phi \alpha \sigma \iota s, M o r .747 \mathrm{~d})$ expresivo al discurso. Y su prosa no renuncia a un encanto que colabora al servicio de la ex-

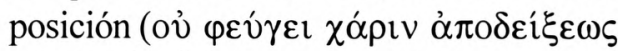

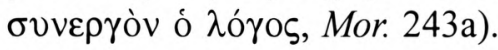

En el Amatorius las metáforas bélicas evocan la imagen de la lucha y el combate en relación con los dos ejes argumentales del diálogo: la conversación en torno a eros y las historias de amor narradas, principalmente la de Bacón e Ismenodora. La proliferación de estas metáforas a lo largo del texto configura un rico entramado de referencias semánticas como telón de fondo que aporta coherencia significativa al diálogo en ambos planos, al tiempo que marca a veces un contraste irónico. Este uso extenso de metáforas e imágenes con presencia dominante en el texto, que crean un marco de referencias verbales y confieren unidad al mismo, constituye precisamente uno de los rasgos más característicos 
del estilo plutarqueo ${ }^{72}$.

\section{Biblografía}

Bravo García, A.,

- "El pensamiento de Plutarco acerca de la paz y la guerra", CFC, 5 (1973) 141-191.

CARNEY, T.F.,

- "Plutarch's style in the Marius", JHS, 80 (1960) 24-31.

Fernández Delgado, J. A.,

- "El estilo de Plutarco en la historia de la prosa griega", EClás, 102 (1992) 31-63.

FLACELIĖRE, R.,

- Plutarque. Oeuvres Morales, t. X, Paris, 1980.

FuHRMANN, M.,

- Les images de Plutarque, Paris, 1964.

HIRSCH-LUIPOLD, R.,

- Plutarchs Denken in Bildern: Studien zur literarischen, philosophischen und religiösen Funktion des Bildhafen, Tübingen, 2002.

KLAERR, R.,

- "Quelques remarques sur le style métaphorique de Plutarque", Actes VIII Congrès Assoc. G. Budé, Paris, 1969, pp. 536-542.
LARMOUR, D.,

- "Metaphor and metonymy in the rhetoric of Plutarch's Parallel Lives", en L. VAN DER STOCKT (ed.), Rhetorical theory and praxis in Plutarch, Louvain-Namur, 2000, pp. 267-279.

LouIs, $\mathrm{P}$,

- Les métaphores de Platon, Rennes, 1945.

VALVERDE, M.,

- "Los símiles en el Erótico de Plutarco", en J. G. MONTES \& M. SÁNCHEZ \& R.J. Gallé (eds.), Plutarco, Dioniso y el vino, Madrid, 1999, pp. 501-516.

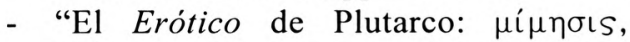

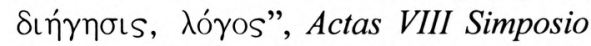
de Plutarco, Barcelona, 2004, (en prensa).

VAN DER StOckT, L.,

- "Aspects of the ethics and poetics of the dialogue in the Corpus Plutarcheum", en I. Gallo \& C. Moreschini (eds.), I generi letterari in Plutarco, Napoli, 2000, pp. 93-116.

WinCKelmanN, A.G.,

- Plutarchi Eroticus et Eroticae narrationes, Turici, 1836.

Véase T. F. CARNEY, 1960, pp. 24 s., que comenta en este sentido la parte central (caps. 11-27) de la Vida de Mario; D. LARmour, 2000, pp. 269-272, que señala cómo en la Vida de Lúculo el personaje aparece asociado a imágenes atléticas y de caza, o en la Vida de César las metáforas marítimas dominan la narración del conflicto de la Guerra Civil; R. HiRSCH-LUIPOLD, 2002, pp. 225-281, que analiza en profundidad las imágenes del ámbito de la medicina presentes en el tratado Ser. num. vind. La construcción de imágenes sostenidas a lo largo de una obra o de un extenso pasaje también es un rasgo de la prosa platónica: cf. P. LouIs, 1945, p. 14 s.; K. Dover, The Evolution of Greek Prose Style, Oxford, 1997, p. 128 s. En Pl., Alc. I, por ejemplo, la imagen del agón es evocada a lo largo de un extenso pasaje con referencia a la rivalidad política: $\alpha v \tau \alpha \gamma \omega v i \zeta \varepsilon \sigma \theta \alpha \imath$

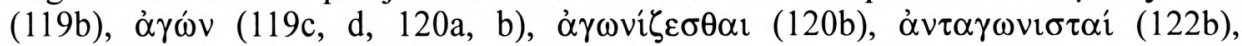
$\delta \imath \alpha \gamma \omega v^{\prime} \zeta \zeta \sigma \theta \alpha \imath$ (123d, e, 124a). 